Research Article

\title{
Study on the Deformation Mechanism of Soft Rock Roadway under Blasting Disturbance in Baoguo Iron Mine
}

\author{
Hong-di Jing $(\mathbb{D}$, Yuan-hui Li, and Kun-meng Li \\ Key Laboratory of Ministry of Education on Safe Mining of Deep Metal Mines, Northeastern University, \\ Shenyang 110819, China \\ Correspondence should be addressed to Hong-di Jing; jinghongdi@163.com
}

Received 21 April 2018; Revised 26 June 2018; Accepted 4 July 2018; Published 1 August 2018

Academic Editor: Franck Poisson

Copyright (C) 2018 Hong-di Jing et al. This is an open access article distributed under the Creative Commons Attribution License, which permits unrestricted use, distribution, and reproduction in any medium, provided the original work is properly cited.

In order to study the deformation mechanism of soft rock roadway in underground mines, it is necessary not only to study the influence of the dynamic disturbance caused by the cyclic mining blasting vibration on the stability of the soft rock roadway but also to study the degradation of the roadway surrounding rock itself and other factors. The paper presented a synthetic research system to investigate the factors that influence roadway rock structure deterioration in Baoguo Iron Mine. Firstly, the stability of rock mass was analyzed from the perspective of the physical and structural characteristics of the rock mass. Afterwards, according to monitoring data of mining blasting vibration, a suitable safety blasting prediction model for Baoguo Iron Mine was determined. And then, combining the results of mining blasting vibration monitoring and deformation monitoring, the effect of cyclic mining blasting on the stability of the soft rock roadway was obtained. By systematically studying the intrinsic factors of rock quality degradation and external environmental disturbances and their interactions, this paper comprehensively explores the deformation mechanism of soft rock roadway and provides the support for fundamentally solving the large deformation problems of soft rock roadway in underground mines.

\section{Introduction}

With the development of the national economy, large-scale geotechnical projects all around China have been increasing, such as the Three Gorges Hydropower Station, South Water Transfer Project, Jinping II Hydropower Station, Jinchuan Gold Mine, and so on. While great achievements have been made, serious challenges have also emerged. The problem of large deformation of soft rock roadway in the underground mines is one of them. It is of great practical significance to study the mechanism of large deformation and ensure the long-term stability of soft rock roadway.

Soft rock roadway project has the following three characteristics. First of all, the structure and environment of the rock mass has become weak, broken, loose, and high ground stress. In addition, the physical and mechanical properties of the rock mass show up as low strength, rheology, easy weathering, and swelling. Thirdly, the engineering characteristics of the surrounding rock show that the roadway pressure is high, the surrounding rock deformation has an obvious time effect, and the stability of the surrounding rock is difficult to control. The research on the deformation mechanism of the soft rock roadway was first conducted by the method of elastic-plastic analysis. The earliest theory was first proposed by Fenner [1] and later Kaiser [2] made another important revision to this calculation method which is still widely used in the international community and appeared in the relevant textbooks. Both Fenner and Kastner assumed that the surrounding rock is an ideal elastoplastic medium, and they considered that the strength of rock mass after failure always maintains the original ultimate strength value. Therefore, the calculated plastic zone radius and deformation displacement of surrounding rock are smaller. For a circular roadway under hydrostatic pressure, Ladanyi gives a closed solution to the deformation of surrounding rock, considering the decrease of formation strength with time, the linear and nonlinear failure of the envelope and the volume expansion effect of formation caused by the failure [3]. Peila studied the stress field and displacement field 
under the interaction between concrete lining structure and rock mass and compared with the finite element method calculation result. The results of the two methods are in good agreement. Peila and Oreste deduced the theoretical calculation method of surrounding rock deformation when the reinforcement zone exists in surrounding rock of tunnel and considered the strain softening mechanical behavior of surrounding rock [5]. Based on the Mohr-Coulomb linear failure criterion, the Leon-Torre parabolic failure criterion, and the Hoek-Brown empirical failure criterion, Roussev deduced the radial displacement of upper part of tunnel under radial internal pressure [6]. In recent years, more and more researches have been done on the influence of rock strain softening and soft rock mineral expansion on the stress and deformation of soft rock roadway. The expansion and expansion of rocks were first observed by Bridgman [4]. Handin measured the expansion of sandstone samples under low confining pressure. The expansion under the effect of deviatoric stress is observed with the time-dependent increase in volume. Since then, many international scholars, such as Paterson, Edmond, Brace, Bienawski, Byerlee, Fridman, and Mogi, have published many experimental results and their analysis based on laboratory experiments [7, 8]. In China, Professor Zongji is the first to link rheology expansion of rock and the deformation of the roadway to research. In an article at the 1983 International Congress of Rock Mechanics, Professor Zongji emphasized the effect of increased volume expansion in the rock mass on the stability of potentially expansive rocks.

The cumulative damage caused by the frequent blasting of underground mines also cannot be ignored. Otuonye studied the dynamic response of roadway roof bolt under the cyclic blasting load and the effect of cyclic blasting load on the roof surrounding rock using DDS technology [9]. Pierce and Napier proposed the effect of seismic circulation on the rock formation when studying underground continuous mining and intermittent mining [10]. Eneva put forward the concept of cumulative combined strain when studying the vibration effect of surrounding rock caused by blasting and rock burst [11]. In addition, he monitored the peak vibration velocity of surrounding rock mass caused by blasting load and the sound velocity of rock mass before and after frequent blasting, and he also studied the accumulated rock mass damage caused by frequent blasting dynamic loads. Ma and Brady studied the cumulative deformation of the surrounding rock mass under cyclic dynamic loading with joints by discrete-element software simulation and on-site monitoring [12]. Ramulu et al. used borehole camera to measure the cumulative damage effect of surrounding rock mass under cyclic blasting [13]. The results show that the high-frequency vibration will cause the damage of rock mass near the rock mass and long-distance rock damage will be caused by the low frequency vibration. Singu investigated the impact damage of adjacent open-air blasting to underground coal mines and used the strain and stress sensors arranged on the roof and pillar to monitor the formation vibration and deformation before and after multiple blasting [14].

In order to study the internal and external factors of deformation mechanism of surrounding rock, our research group studied all kinds of factors that affect the deformation of soft rock roadway in underground mines. The research

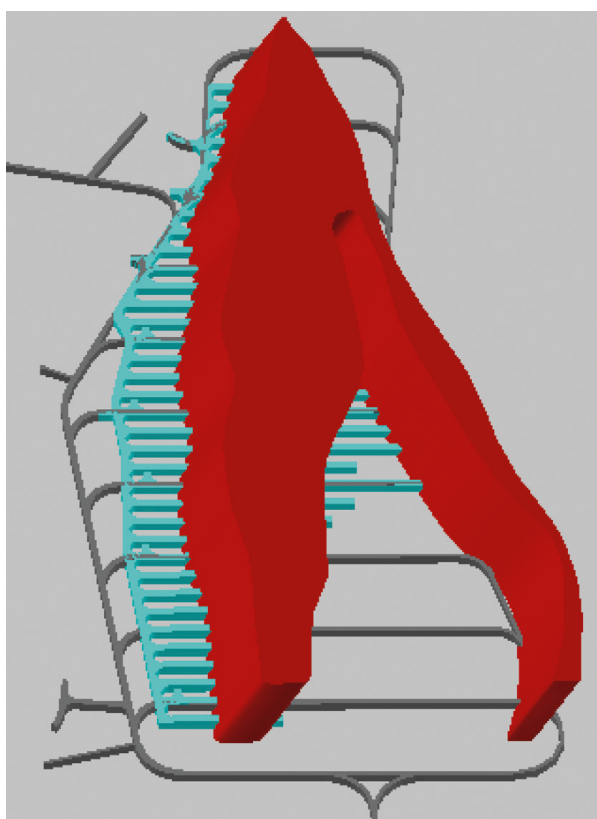

FIgURE 1: Nonpillar sublevel caving mining in Baoguo Iron Mine.

mainly includes the stability evaluation of rock mass, the extraction and statistics of structural surface information, the influence of clay minerals on the stability of roadway, the analysis of the influence of frequent blasting disturbance on the deformation of surrounding rock, and so on.

\section{Geology and Engineering Background}

Baoguo Iron Mine is located $50 \mathrm{~km}$ northeast of Beipiao City in Liaoning Province. Geological coordinates of the mine center: longitude $121^{\circ}$ and north latitude $42^{\circ}$. It is located in the hilly area, and due to the different lithology, the terrain is high in the periphery and low in the middle. The mining area belongs to the northern temperate monsoon climate zone. According to the meteorological data in Beipiao City, the annual rainfall is $494.19 \mathrm{~mm}$, and the annual rainfall is mostly concentrated in June and July. There are $40 \mathrm{~m}$ to $60 \mathrm{~m}$ wide seasonal valleys on both sides of the east and west of the Baoguo Iron Mine. The largest river near the mining area is Baoguolao River, with a total length of more than $40 \mathrm{~km}$. It flows through the mining area from northwest to southeast and there will be floods in the rainy season.

The lithology is mainly composed of mixed rocks and amphibolite, followed by garnet amphibolite and pyroxene amphibolite. The iron deposits mainly occur in the metamorphic rock strata that inclined to the southeast.

Baoguo Iron Mine uses nonpillar sublevel caving method. The layout and components of the mine are as follows: the direction of the stopes is vertical to the ore bodies, and its length is approximately equal to the thickness of the ore body. The mine has a midsection of $60 \mathrm{~m}$ and a segment height of $15 \mathrm{~m}$. The layout of the mining roadway is along the vertical ore body and the distance between adjacent mining roadways is $15 \mathrm{~m}$. The upper and lower adjacent sublevels are diamond-shaped layout. Figure 1 shows a single sublevel layout of Baoguo Iron Mine. 


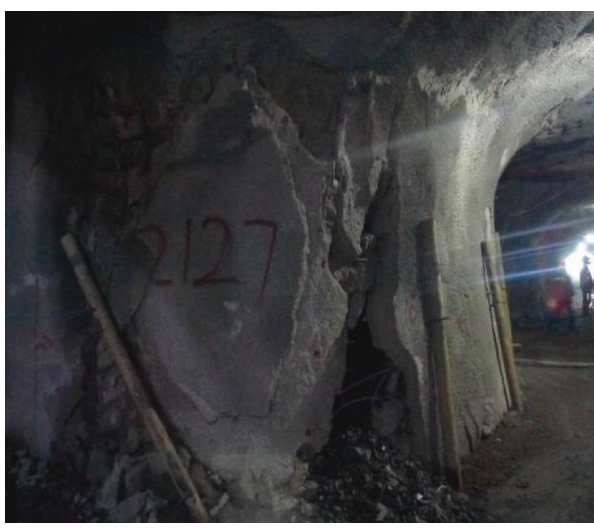

(a)

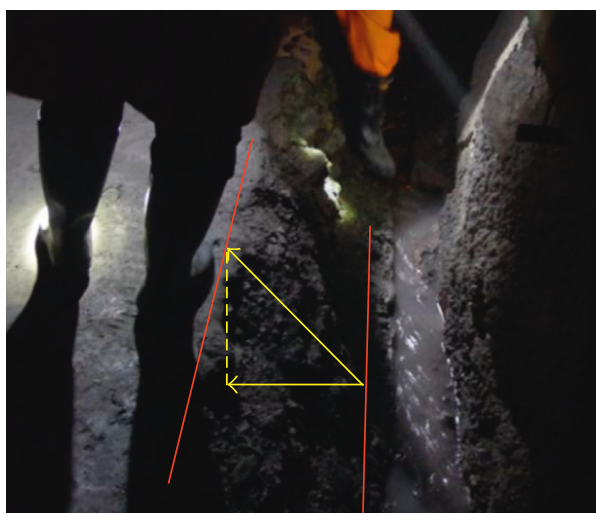

(c)

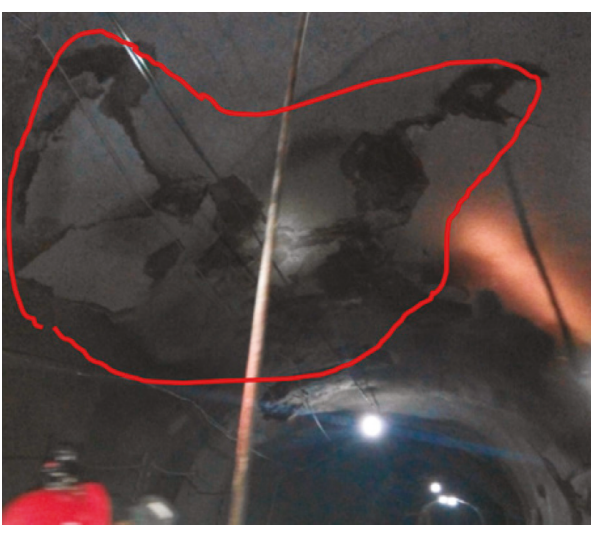

(b)

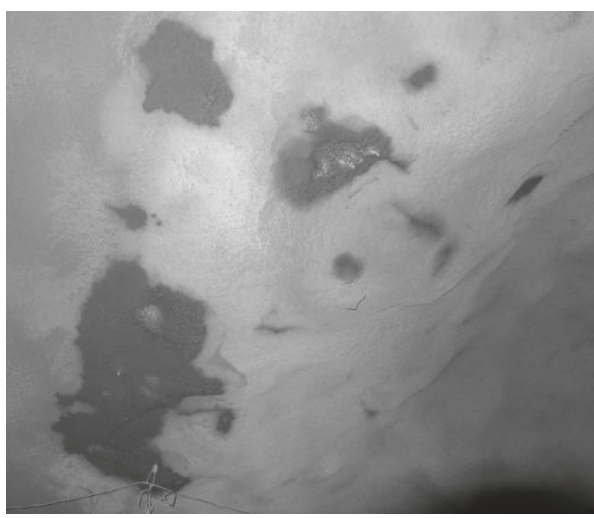

(d)

Figure 2: Different destruction modes of expansive soft rock roadway. (a) Pillar failure, (b) roof falling, (c) roadway floor heave, and (d) water seepage deformation.

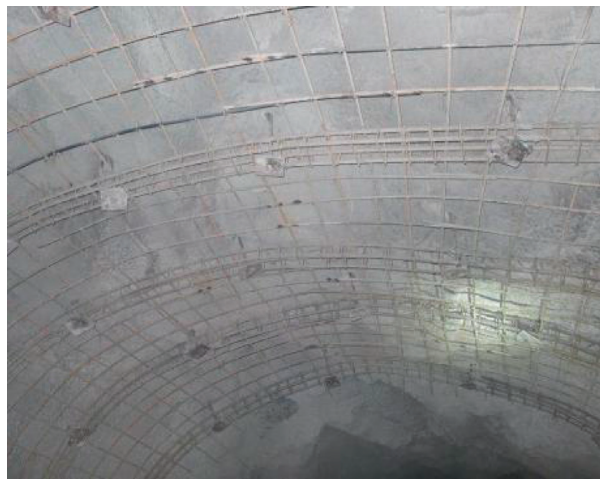

(a)

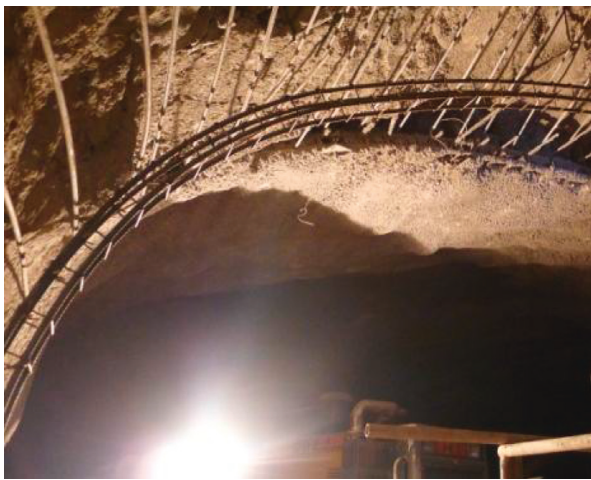

(b)

FIGURE 3: Support status of the main haulage roadway. (a) Bolt-mesh support and (b) steel arch support.

The ore body of Baoguo Iron Mine has complex conditions. The surrounding rock of the ore body is generally affected by structure and alteration, which leads to many stability problems, such as low compressive strength, water damage, deformation caused by expansion, and so on. As a result, the roadway deforms and cracks quickly after the excavation of the roadway, resulting in the weakening of the surrounding rock such as scaling, roof falling, and settling, which seriously affect the mining and transportation of the mine (Figure 2).
On-site investigation reveals that the main supports for Baoguo Iron Mine are anchors, anchor mesh, steel arch, and shotcrete. The support sequence is first to spray concrete, then install anchor bolt and anchor mesh and steel arch (Figure 3), and finally spray the concrete again. Due to the poor stability of the surrounding rock, concrete must be sprayed immediately after excavation. Anchor support is mainly used to suspend crushed rock and anchor mesh used to protect the space between them. Subsequent steel arch fixed the overall shape to prevent large-scale deformation. 
In the last step, spray concrete again to cover the entire roadway surrounding rock.

The complex geologic conditions of Baoguo Iron Mine determine the supporting scheme. The surrounding rock of the mine's ore body is affected by the structure and alteration, which lead to the stability of the main haulage roadway obviously weakened. At present, the main problems of roadway support status are as follows:

(1) Inability to reach the original support target, and there is cracking, falling, and scaling in some areas.

(2) The support construction is mainly rigid, so the stress inside the surrounding rock cannot be released, finally resulting in stress raisers and damage expanded.

(3) High rework ratio and frequent maintenance lead to high support costs.

In order to investigate the deformation mechanism of soft rock roadway and solve the field problem of large-scale damage in Baoguo Iron Mine, a series of researches and analyses were conducted in the view of physical characteristics, structural features, daily blasting disturbance in production, and macroscopic deformation of surrounding rock. Finally, to solve the large-scale damage and significant floor heave phenomenon of soft rock roadway with large deformation. We conduct research and analysis, respectively, from the aspects of physical characteristics, structural features, blasting disturbance in daily production, and macroscopic deformation of surrounding rock.

\section{Analysis of Rock Mass Physical and Structural Features}

In order to clarify the deformation mechanism of roadway, first of all, we must have a basic understanding of the conditions of rock mass. Surrounding rock has great difference in strength, clay content, structural plane and plastic deformation, and other characteristics, which results in different rock properties, different microstructures, and differences in the development of the structural planes in the rock masses. Finally, the mechanical properties of rock mass and the stability of roadway engineering are full of uncertainties [15].

\subsection{Structural Surface Information Extraction. A large} number of engineering examples show that the structural planes often affect the stability of the underground project. The distribution of structural plane is one of the important indexes for evaluating the rock mass quality. Studying the characteristics of the structural plane and evaluating the quality of the rock mass are of great significance to mine safety mining.

The structural plane is planar geological interface with different directions, sizes and morphologies in the rock mass. The theory of rock mass structure states that the rock mass is divided by a variety of structural planes, including joints, faults and weak layers. In underground rock engineering such as mine engineering and tunnel engineering, the development of the structural plane plays a key role in the rock mass strength, deformation and stability. Therefore, the extraction of structural surface information in the rock mass engineering is an important geological survey. The accuracy and efficiency of the traditional method for collecting information of structural plane are low and the working intensity of surveyors is large. The use of three-dimensional imaging technology to survey structural plane information has tremendous advantages over traditional measurement methods, which makes it possible to acquire rock mass structure information quickly, accurately, and safely in harsh and complicated experimental conditions.

The original 2D image data was collected by CAE image acquisition system. Then the Sirovision image processing software system was used to synthesize the two-dimensional images collected by field work into $3 \mathrm{D}$ images. Then the actual coordinates of the control points of the surrounding rock faces were used for geographical positioning. Finally, the $3 \mathrm{D}$ images that are positioned are spliced to complete the reconstruction of $3 \mathrm{D}$ mine roadway. Next, information of rock mass structural plane can be extracted and calculated with $3 \mathrm{D}$ roadway model. According to the extracted roadway rock mass plane information, we can set up the rock mass structural plane information analysis groups (Figure 4). At last, the overall stability analysis results of rock mass can be obtained according to the structural plane information among different analysis groups (Figures 5 and 6).

According to the result of investigation and analysis on the structural plane of Baoguo Iron Mine roadway, the information such as the main joint orientation, the dip direction, dip angle, and the spacing of joint planes of the surrounding rock and ore body are determined. At the same time, the influences of the structure on the stability of the surrounding rock in the monitoring roadway are as follows:

(1) The joint dip directions are mainly distributed around $90^{\circ}$ and the joint dip angles are generally steeper and mainly distributed between $50^{\circ}$ and $70^{\circ}$. Finally, it is determined through statistics that the dominant structural planes in surrounding rock are one group, $88^{\circ} \angle 54^{\circ}$.

(2) The distribution of joint spacing in surrounding rock ranges from $0.1567 \mathrm{~m}$ to $0.4128 \mathrm{~m}$ and concentrated on $0.2 \mathrm{~m}$. The distribution of joints in the ore bodies ranges from $0.1142 \mathrm{~m}$ to $0.9611 \mathrm{~m}$ and the average spacing is $0.5 \mathrm{~m}$. The average spacing of joints in the ore bodies is larger than that in surrounding rock, and the degree of joints development in the ore bodies is lower than that in surrounding rock.

(3) There is no wedge structure in ore body monitoring points. However, surrounding rock monitoring point data show more wedge structures. The wedge structures appear near the fault around the main haulage roadway most frequently, which proves that the rock mass has been broken in this area and the roof stability is very poor.

3.2. On-Site Point Loading Strength Test. In order to evaluate the quality of rock mass exactly, it is necessary to obtain the tensile strength and compressive strength of ore and 


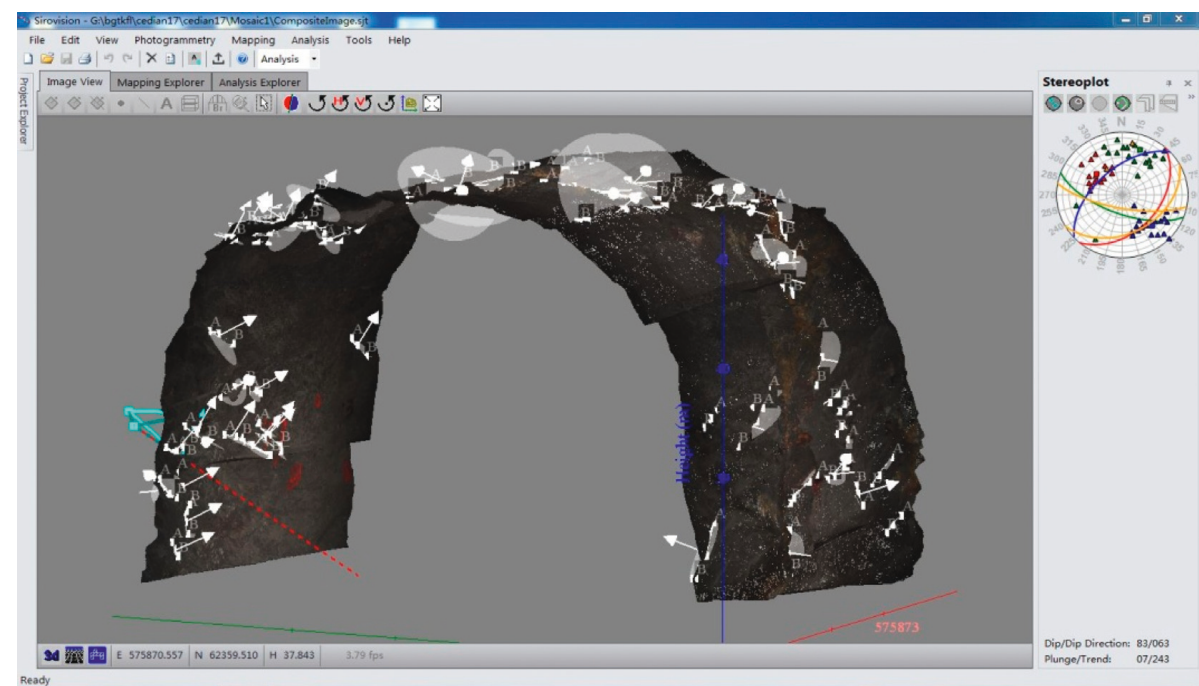

FIGURE 4: Sirovision stereo image analysis system.

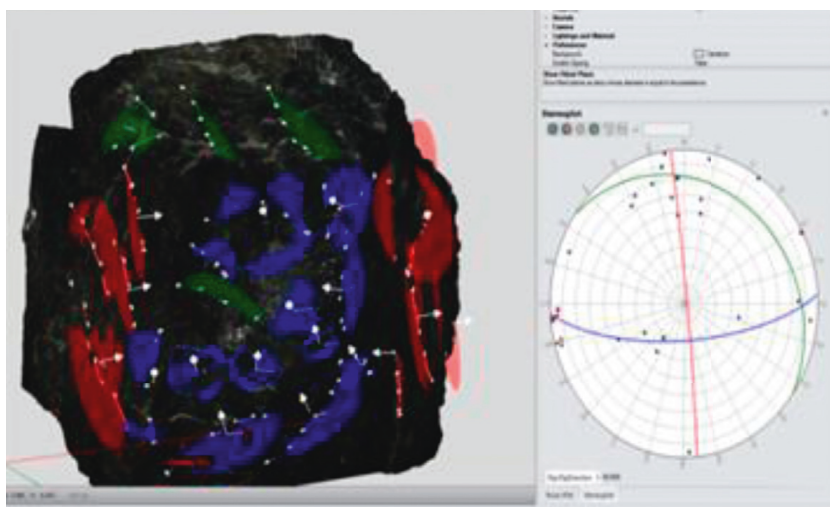

FIgURE 5: Structural plane information analysis groups.

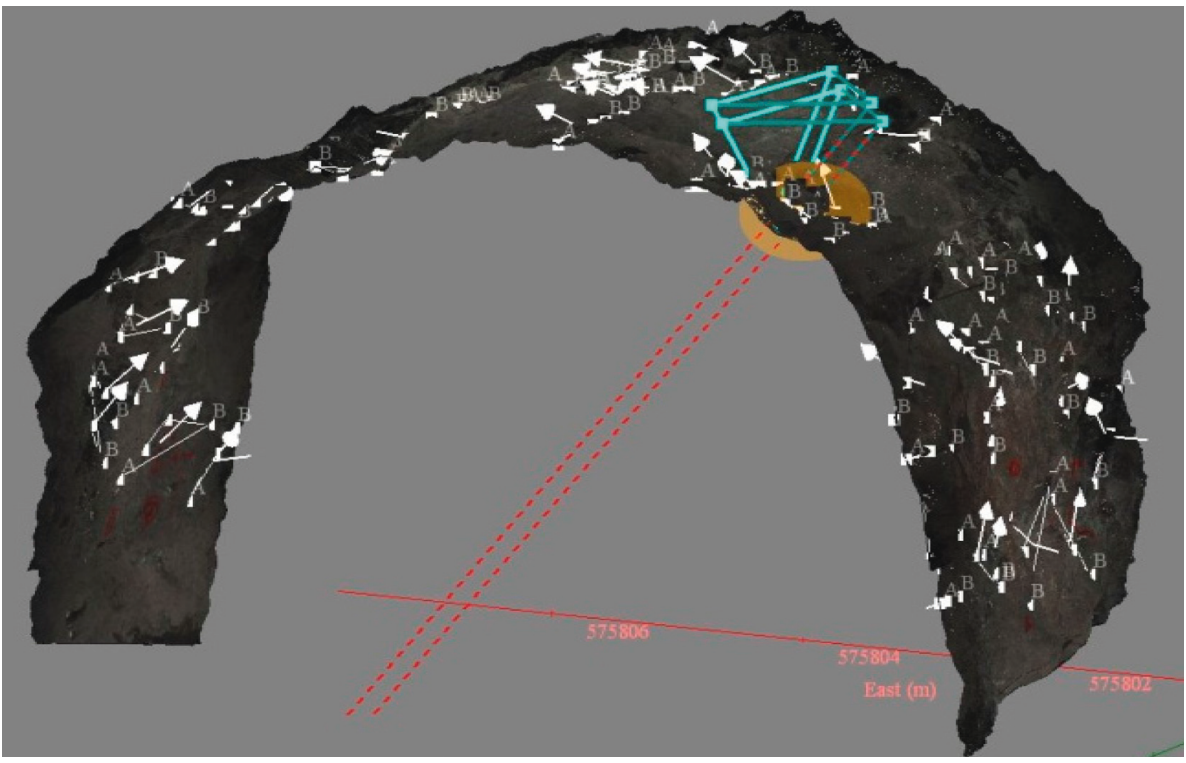

Figure 6: Analysis of roadway rock wedges.

surrounding rock of the mine. A large number of surrounding rocks and ores were selected, respectively, in the $+20 \mathrm{~m}$ section of the Baoguo Iron Mine for the on-site point loading strength test. Next, the tensile strength and compressive strength of the ore and the surrounding rock were obtained. After the on-site point loading strength test, the 


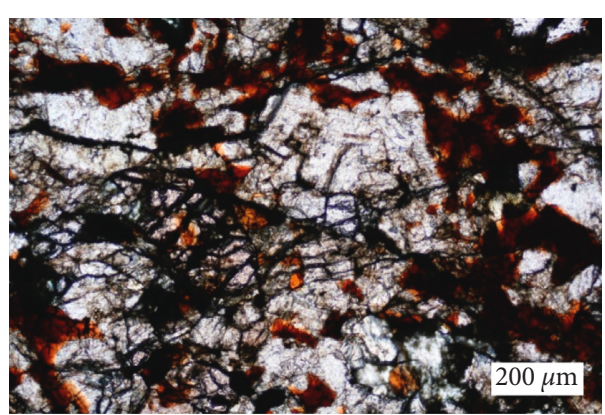

(a)

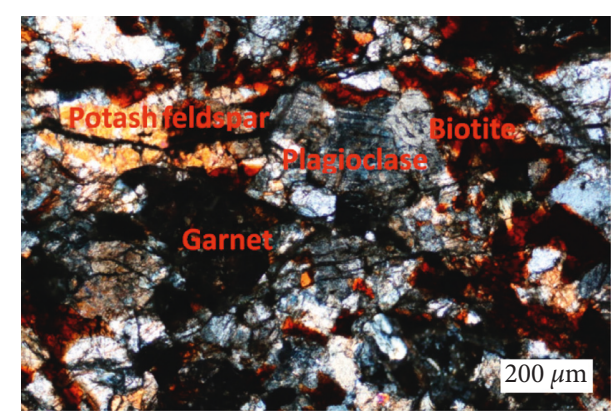

(b)

Figure 7: Results of SEM scanning in Baoguo Iron Mine. (a) Plane polarized light $(\times 50)$ and (b) perpendicular polarized light $(\times 50)$.

average load of surrounding rocks is $5.64 \mathrm{kN}$, while the average load of ores is $17.74 \mathrm{kN}$. There is a good correlation among rock point loading strength, rock tensile strength, and rock compressive strength. According to the formula given by International Society of Rock Mechanics (ISRM), the rock tensile strength and compressive strength can be obtained by point loading strength index. The formulas are as follows:

$$
\begin{aligned}
& R_{\mathrm{t}}=1.25 I_{\mathrm{s}(50)}, \\
& R_{\mathrm{c}}=15.8+12.27 \times I_{\mathrm{s}(50)},
\end{aligned}
$$

where $I_{\mathrm{s}}(50)$ is the point loading strength index; $R_{\mathrm{t}}$ is the tensile strength; and $R_{\mathrm{c}}$ is the compressive strength.

The tensile strength $\left(R_{\mathrm{t}}\right)$ and compressive strength $\left(R_{\mathrm{c}}\right)$ of the ore specimens collected in the +20 section of Baoguo Iron Mine were calculated as follows: $6.7 \mathrm{MPa}$ and 81.567 MPa. At the same time, the tensile strength and compressive strength of the rock specimens were calculated as follows: $2.9 \mathrm{MPa}$ and $44.266 \mathrm{MPa}$. It can be seen that the strength of rock is significantly lower than that of ore. However, the main haulage roadway is just located in the rock with lower strength. So, the stability of the main haulage roadway is much worse than that in the ore body.

\subsection{Influence of Clay Minerals on Stability of Rock Mass.} In the soft rock underground engineering, the phenomenon of clay minerals swelling with water is a difficult problem. The basic factors affecting the properties of swellable soft rock are internal and external factors. Internal factors include three components: rock component (mineral composition, chemical composition, and particle size), natural water content, and the degree of cementing. External factors are mainly water changes and internal stress changes caused by mining activities. The special geological conditions in the soft rock mine lead to the volume expansion of clay minerals after water absorption, which is the main reason for the deterioration of rock mass. Most of the natural rock masses are anisotropic discontinuous medium, and there are inevitably joints and fractures with different characteristics [16]. When in a water-rich environment, the water will move along the fissures in the rock mass so that water and rock mass influenced each other. The groundwater in fractures changes the structure of fractures in the rock mass through osmotic pressure and physical and chemical actions [17]. The hydrophilic ability of clay minerals varies with different compositions. Studies have shown that montmorillonite has a huge expansion capacity, followed by illite, and kaolinite is the weakest. The huge swelling ability of montmorillonite is due to its strong cation exchange capacity, and the absorbed water causes the volume to expand rapidly. Due to the strong expansibility of clay minerals, studying the mechanism of water swelling of clay minerals in soft rock roadways is of great significance to study the deformation mechanism of underground soft rock roadway.

The ore body of Baoguo Iron Mine is Anshan-type sedimentary iron ore in Chaoyang, Liaoning Province. Random sampling was carried out along the roadway in the mining level. Scanning electron microscopy (SEM) and X-ray diffraction were used to study the composition of clay minerals. The partial of the SEM scan results of Baoguo Iron Mine gneiss are shown in Figure 7 . The rock sample is mainly gneiss with pomegranate biotite and potash feldspar. Rock samples have black-green, plate-like crystal and massive structure characteristics. Mineral composition is as follows: $37.7 \%$ of plagioclase, $10 \%$ of potassium feldspar, $22.5 \%$ of biotite, $13 \%$ of garnet, and $16.8 \%$ of clay minerals. Potash feldspar showed its shape plate, cleavage development, weak clay, large changes in particle size, and particle size in the $0.3-20 \mathrm{~mm}$; plagioclase was semi-self-plate, visible polycrystalline twin, and weak sericite, and the particle size is more than $0.5-1 \mathrm{~mm}$; biotite was flaky and reddish brownbrown and showed the flow parallel to the orientation, uneven aggregation distribution, and particle size more in $0.2-1.5 \mathrm{~mm}$; garnet was granular and light brown and showed solution reason more developed and the particle size more than $0.2-0.5 \mathrm{~mm}$.

$\mathrm{X}$-ray injected into the crystal lattice of clay minerals will produce diffraction phenomenon. Different clay minerals and lattice structures will produce different diffraction patterns. According to the laminar structure characteristics of clay minerals, the X-ray diffraction principle and diffraction peaks, mineral species, and the percentage of various clay minerals in the sample can be quantitatively determined. The swelling of soft rock has a direct relationship with the content of clay minerals. For example, the research results show that when the content of montmorillonite is more than $7 \%$ or the content of illite is more than $20 \%$, the soft rock has obvious expansion characteristics. And the higher content, the greater expansion ratio. For this reason, X-ray diffraction (XRD) analysis method can be used to determine the type and 
TABLE 1: Clay mineral X-ray diffraction analysis results.

\begin{tabular}{lcccccc}
\hline & \multicolumn{6}{c}{ Clay minerals relative content (\%) } \\
\hline Clay mineral & $\mathrm{S}$ & $\mathrm{I}$ & $\mathrm{K}$ & $\mathrm{C}$ & $\mathrm{I} / \mathrm{S}$ & $\mathrm{C} / \mathrm{S}$ \\
Content & 93 & 2 & 2 & 3 & - & - \\
\hline
\end{tabular}

S: montmorillonite; I/S: illite/montmorillonite; I: illite; K: kaolinite; C: chlorite; C/S: chlorite/montmorillonite.

TABle 2: Classification criterion of swelling soft rock by $\mathrm{He}$ Manchao.

\begin{tabular}{lccc}
\hline Classification & $\begin{array}{c}\text { Montmorillonite } \\
\text { content (\%) }\end{array}$ & $\begin{array}{c}\text { Dry saturated } \\
\text { water } \\
\text { absorption } \\
\text { ratio (\%) }\end{array}$ & $\begin{array}{c}\text { Free expansion } \\
\text { deformation } \\
\text { ratio (\%) }\end{array}$ \\
\hline $\begin{array}{l}\text { Poor } \\
\text { expansibility }\end{array}$ & $<10$ & $<20$ & $<10$ \\
$\begin{array}{l}\text { Medium } \\
\text { expansibility }\end{array}$ & $10 \sim 30$ & $20 \sim 50$ & $10 \sim 15$ \\
$\begin{array}{l}\text { Strong } \\
\text { expansibility }\end{array}$ & $>30$ & $>50$ & $>15$ \\
\hline
\end{tabular}

percentage of clay minerals, which can also be used to judge the impact of clay minerals on stability of soft rock roadway in underground mines. According to X-ray diffraction analysis results presented in Table 1 and SEM results, the content of montmorillonite in surrounding rock is $15.624 \%, 0.336 \%$ for illite, $0.336 \%$ for kaolinite, and $0.504 \%$ for chlorite.

After obtaining the proportions of different expansive clay minerals, the expansibility of clay minerals can be graded through the classification criterion of swelling soft rock by He Manchao in Table 2, and then the expansibility level of the main haulage roadway can be clarified.

In addition to the montmorillonite content, indicators in the expansive rock determining include dry saturated water absorption ratio and free expansion deformation size. The samples of the expansive rock were taken from the main haulage roadway at the $-40 \mathrm{~m}$ level in order to ensure that the samples were unweathered. A total of 15 samples were collected in the experiment, $50 \mathrm{~g}$ of every sample was used to test the dry saturated water absorption ratio, and the rest of the samples was used to test the free expansion and deformation size. The test results are shown in Table 3.

Different clay mineral contents can be obtained relying on X-ray diffraction tests; the average content of Montmorillonite is $15.62 \%$, the average dry saturated water absorption ratio is $32.95 \%$ and the average-free expansion deformation ratio is $21.24 \%$. Applying the expansibility soft rock grading criterion, the surrounding rock of the main haulage roadway of Baoguo Iron Mine belongs to medium expansibility swelling soft rock, which is easy to failure after being soaked in water. In addition, the expansibility soft rock also has a high water absorption capacity, and its water absorption capacity is clearly controlled by the exchangeable cations. Expansive rock mass is easy to produce rheology under engineering stress, of which expansion deformation is mainly composed of creep, relaxation, and elastic aftereffect. Among them, creep refers to the phenomenon that the deformation increases with time when the load is constant,
TABLE 3: Hydraulic properties of swelling soft rock samples.

\begin{tabular}{lcc}
\hline Number & $\begin{array}{c}\text { Dry saturated water } \\
\text { absorption ratio (\%) }\end{array}$ & $\begin{array}{c}\text { Free expansion } \\
\text { deformation ratio (\%) }\end{array}$ \\
\hline PZ-01 & 20.14 & 13.15 \\
PZ-02 & 44.33 & 30.02 \\
PZ-03 & 28.34 & 13.80 \\
PZ-04 & 34.40 & 25.06 \\
PZ-05 & 26.96 & 13.69 \\
PZ-06 & 31.37 & 23.38 \\
PZ-07 & 26.66 & 13.65 \\
PZ-08 & 39.92 & 27.57 \\
PZ-09 & 44.14 & 29.85 \\
PZ-10 & 28.03 & 14.02 \\
PZ-11 & 45.46 & 31.12 \\
PZ-12 & 54.90 & 36.40 \\
PZ-13 & 16.69 & 10.13 \\
PZ-14 & 21.40 & 13.42 \\
PZ-15 & 31.46 & 23.28 \\
\hline
\end{tabular}

relaxation refers to the phenomenon that the stress decreases with the passage of time when the strain remains constant, and the elastic aftereffect refers to the phenomenon that the elastic strain lags behind the stress when loading or unloading. We know that because of the complex and changeable conditions of the underground engineering rock mass, the rock properties are difficult to interpret. Therefore, if we want to study the deformation mechanism of large deformation soft rock roadway, we not only need to experiment in the laboratory to get the physicochemical and structural characteristics of rock mass, but also should test the influence of daily production disturbance on the stability of underground roadways.

\section{Blasting Vibration Monitoring Research}

In the mining process of pillarless sublevel caving mining method, rock blasting is the main method used. The main characteristics of mining blasting are mainly large amount of explosives, frequent blasting, and multipoint blasting. The impact of frequent blasting in underground mine engineering has the characteristics of long-term and repetitive. Various destruction effects have been continuously strengthened with the effect of accumulated load caused by blasting over time. Then, the damage accumulation inside the rock and the creep effect follows. When the accumulated load exceeds the critical value of surrounding rock stability, the roadway failure will occur.

The impact of blasting vibration on the surrounding rock can be summarized as the following three aspects:

(1) Burst loading not only increases the shear stress in the rock, but also expands the primary structural plane. At the same time, the secondary structural plane will be produced, which affects the overall stability of the surrounding rock.

(2) Blasting loading changes the state of the groundwater and changes the moisture content and the osmotic pressure at the existing mezzanines or fractures. This will affect the slip resistance of the contact surface directly. 
(3) During the process of frequent blasting disturbance, the strength and deformation of rock mass area affected by blasting will be significantly increased.

In order to explore the impact of blasting vibration on the deformation of main haulage roadway, a blasting vibration monitoring station was set up near blasting point. Through analyzing the data of blasting vibration waves, the influence of blasting vibration on the stability of large deformation soft rock roadway has been obtained.

4.1. Multipoint Differential Blasting Analysis. In general, the blasting vibration monitoring signals are generated by a single detonating source. The distance and the maximum single detonating charge weight and other data can be directly applied. By using the principle of regression and taking the resultant velocity and the proportional distance as variables, the relationship between the resultant velocity and the proportional distance will be obtained and then the multipoint differential blasting analysis can be acquired. The multipoint differential blasting has already been the most commonly used method in the daily production of Baoguo Iron Mine. However, there are different distances between detonating points and monitoring points, which increase the signal recognition difficulty.

The factors that affect blasting vibrations are extremely complex, so it is very difficult to build predictive models by taking all the factors into account. Blasting vibration monitoring data show that the main factors that impact on blasting vibration strength are the amount of explosives and the distance from the detonating point to the monitoring point. Therefore, Sadov's formula is used to describe the vibration intensity:

$$
v=K\left(\frac{\sqrt[3]{Q}}{R}\right)^{\alpha}
$$

In the formula, $v$ represents the particle vibration velocity $(\mathrm{cm} / \mathrm{s}), Q$ is the maximum single explosive amount $(\mathrm{kg}), R$ is the distance from the detonating point to the monitoring point, $K$ is the coefficient related to the medium, $\alpha$ is the coefficient of the vibration wave decreasing with distance, and $R / Q^{1 / 3}$ is called the proportional distance. $v$ and $R$ are, respectively, expressed as follows:

$$
\begin{aligned}
& v=\sqrt{v_{x}^{2}+v_{y}^{2}+v_{z}^{2}}, \\
& R=\sqrt{X^{2}+Y^{2}+Z^{2}} .
\end{aligned}
$$

Taking the particle velocity and the proportional distance as variables, according to Sadov's formula, the relationship between the resultant velocity $V$ and the proportional distance $R_{\mathrm{m}}=R / Q^{1 / 3}$ can be found by the regression principle, and then $K$ and $\alpha$ will be obtained to establish a suitable blasting vibration prediction model.

Take the case of blasting at the $+35 \mathrm{~m}$ level on May 13: for example, the blasting program at the $+35 \mathrm{~m}$ level is shown in Table 4. Blasting operations involve three roadways with different distances and explosive amount. Therefore, the
TABLE 4: Blasting parameters at $+35 \mathrm{~m}$ on May 13 .

\begin{tabular}{lccc}
\hline $\begin{array}{l}\text { Blasting } \\
\text { level }\end{array}$ & $\begin{array}{c}\text { Roadway } \\
\text { number }\end{array}$ & Detonators & $\begin{array}{c}\text { Explosive } \\
\text { weight }(\mathrm{kg})\end{array}$ \\
\hline \multirow{3}{*}{$+35 \mathrm{~m}$} & $8 \#$ & 3 sections & 485 \\
& $9 \#$ & 5 sections & 556 \\
& $11 \#$ & 9 sections & 590 \\
\hline
\end{tabular}

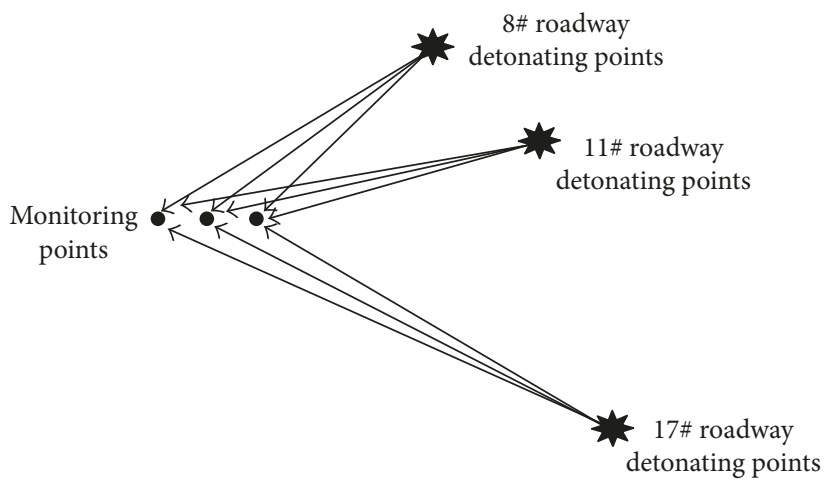

- Monitoring points

Detonating points

Figure 8: Multipoint differential blasting signal reception schematic.

monitored signals are complex; the interactions of the monitored signals are difficult to separation. The burst schematic is shown in Figure 8.

As can be seen from the above tables, there are a total of three blasting sites in the blasting test in different roadways, which are $8 \#$ roadway, $9 \#$ roadway, and $11 \#$ roadway on the $+35 \mathrm{~m}$ level. The explosives amounts are $485 \mathrm{~kg}, 556 \mathrm{~kg}$, and $545 \mathrm{~kg}$, respectively; the proportions of the distance are $10.22 \mathrm{~m} / \mathrm{kg}^{1 / 3}, 9.87 \mathrm{~m} / \mathrm{kg}^{1 / 3}$, and $8.46 \mathrm{~m} / \mathrm{kg}^{1 / 3}$, respectively. As shown in Table 5, the test equipment recorded the 3 blasting signals mainly with particle vibration velocities of $3.658 \mathrm{~cm} / \mathrm{s}$, $1.213 \mathrm{~cm} / \mathrm{s}$, and $6.050 \mathrm{~cm} / \mathrm{s}$. According to Sadov's formula, the vibration velocity decreases with the increase of the proportional distance. Based on the relationship and blasting monitoring data, the problem of analyzing multipoint blasting signals can be solved. After the determination, 8\# roadway blasting corresponds signal 2, 9\# roadway blasting corresponds signal 1, and 11\# blasting roadway corresponds signal 3. By using this method, the long-term monitoring blasting vibration data are, respectively, analyzed, and the prediction model of the blasting vibration peak velocity can be determined.

4.2. Blasting Vibration Test Results Analysis. The Sadovsky formula and blasting vibration safety standards in "Safety Regulations for Blasting (GB6722-2014)" [18] are applied to the analysis of blasting vibration signals. Therefore, the influence of blasting on the soft rock roadway was studied based on the main vibration frequency and the peak particle velocity. Afterwards, the blasting vibration prediction model of Baoguo Iron Mine was obtained by regression fitting. Then the safe blasting distance and the corresponding safe single detonating charge weight can also be obtained. 
TABLE 5: Blasting vibration velocities at monitoring station 3 on May 13.

\begin{tabular}{lcccc}
\hline Signal number & $X(\mathrm{~cm} / \mathrm{s})$ & $Y(\mathrm{~cm} / \mathrm{s})$ & $Z(\mathrm{~cm} / \mathrm{s})$ & Resultant velocity $(\mathrm{cm} / \mathrm{s})$ \\
\hline Signal 1 & 3.514 & 1.807 & 2.672 & 3.658 \\
Signal 2 & 1.538 & 1.697 & 1.312 & 1.213 \\
Signal 3 & 3.608 & 4.831 & 3.682 & 6.050 \\
\hline
\end{tabular}

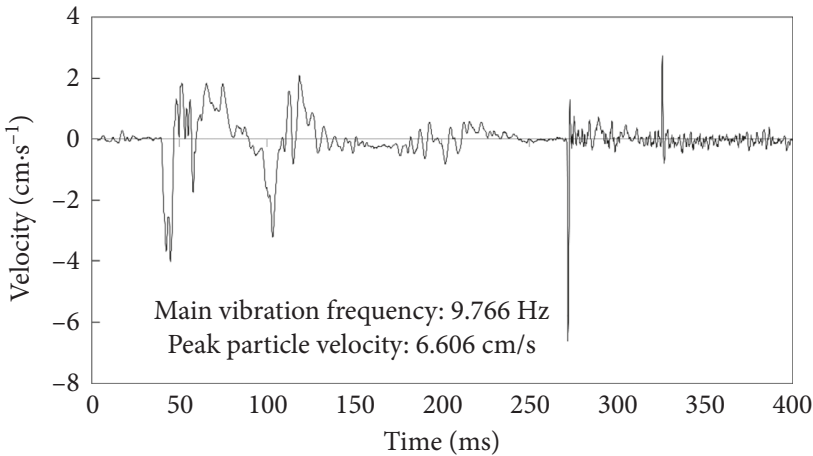

(a)

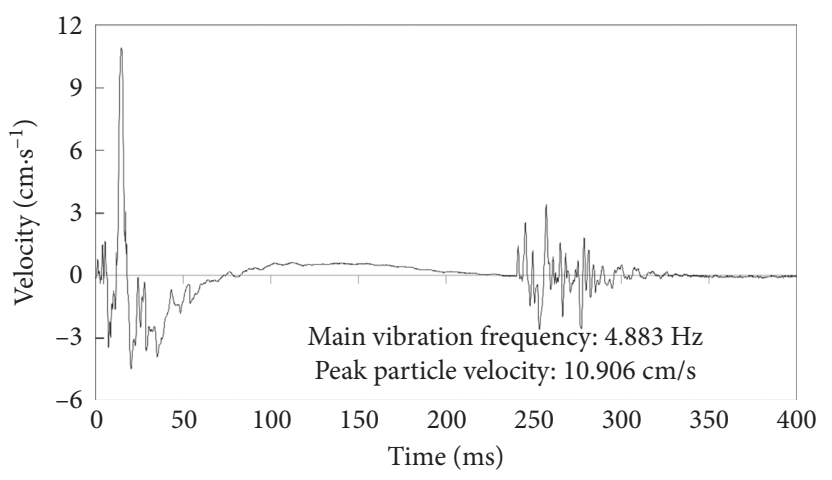

(c)

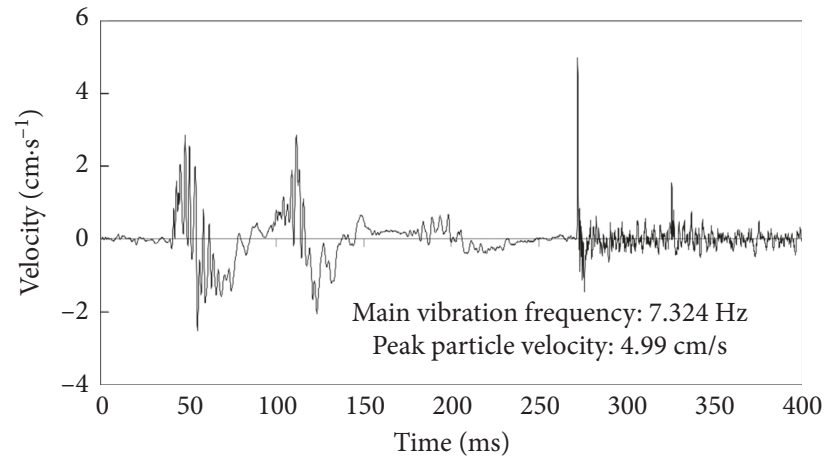

(b)

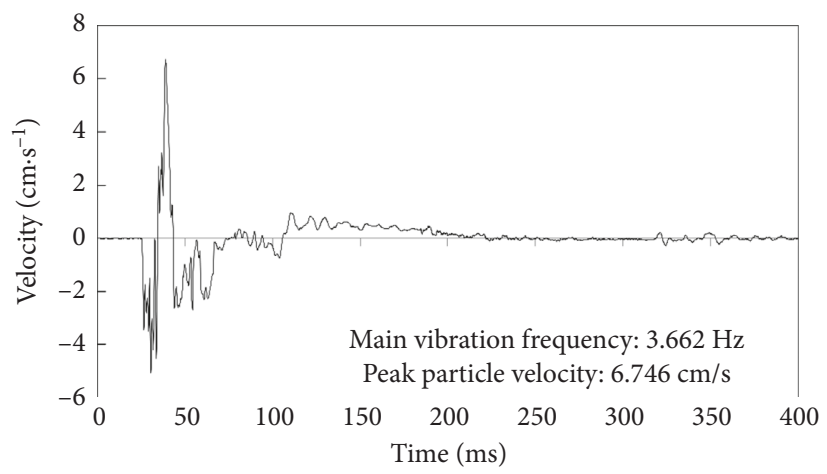

(d)

FIGURE 9: Velocity-time curves of partial measured blasting vibration signals.

The data monitored by the blasting vibration meter can be used to obtain information such as peak particle velocity and main vibration frequency. Part of the measured blasting vibration signals are as follows (Figure 9).

Based on the statistical analysis of the on-site blasting vibration signals, it can be concluded that the main vibration frequencies of the blasting vibration signals are almost less than $10 \mathrm{~Hz}$. The safety standard of blasting vibration in "Safety regulations for blasting (GB6722-2014)" is shown in Table 6. According to GB6722-2014 and main vibration frequency, it is possible to obtain the safety peak particle velocity (PPV). As a result, the safety PPV of the main haulage roadway of Baoguo Iron Mine should be less than $18 \mathrm{~cm} / \mathrm{s}$.

Part of blasting vibration monitoring data has been shown in Table 7.

$K$ and $\alpha$ in Sadov's formula are calculated by using the binary regression method. In (2), take the logarithm, let $y=\ln v, x=\ln \left(R / Q^{1 / 3}\right), a=\alpha, b=\ln K, y=a x+b$. Afterwards, the least squares method can be used to obtain the values of $a$ and $b$ and then $K$ and $\alpha$. The attenuation formula of blasting vibration velocity in Baoguo Iron Mine is shown in (4). The curve of blasting vibration velocity with the proportional distance is shown in Figure 10.

$$
v=208.169\left(\frac{\sqrt[3]{Q}}{R}\right)^{1.830}
$$

There are many schemes to eliminate the hazard of mining blasting vibration. With the increase of the maximum single detonating charge weight, the particle vibration velocity increases. At present, the maximum single detonating charge weight of Baogang iron mine is mainly between $500 \mathrm{~kg} \sim 650 \mathrm{~kg}$. After obtaining the maximum vibration velocity and distance, the safety maximum single detonating charge weight (Table 8) and the safety variation map (Figure 11) corresponding to each distance can be obtained from (4). It can be seen from Table 7 that when the distance is $35 \mathrm{~m}$, the allowable safety maximum single detonating charge weight is $574.83 \mathrm{~kg}$, which is close to the actual single detonating charge weight of Baoguo Iron Mine. If the distance is less than $35 \mathrm{~m}$, the actual single detonating charge weight will be higher than the allowable charge weight. Therefore, controlling the influence of mining blasting vibration on the stability of the main haulage roadway should start to reduce the maximum single detonating charge weight within $35 \mathrm{~m}$. 
TABLE 6: Safety standard of blasting vibration.

\begin{tabular}{|c|c|c|c|c|}
\hline \multirow{2}{*}{ Number } & \multirow{2}{*}{ Protected object class } & \multicolumn{3}{|c|}{ Safety PPV $(\mathrm{cm} / \mathrm{s})$} \\
\hline & & $f \leq 10 \mathrm{~Hz}$ & $10 \mathrm{~Hz}<f \leq 50 \mathrm{~Hz}$ & $f>50 \mathrm{~Hz}$ \\
\hline 1 & Adobe house & $0.15 \sim 0.45$ & $0.45 \sim 0.9$ & $0.9 \sim 1.5$ \\
\hline 2 & General civil buildings & $1.5 \sim 2.0$ & $2.0 \sim 2.5$ & $2.5 \sim 3.0$ \\
\hline 3 & Industrial and commercial buildings & $2.5 \sim 3.5$ & $3.5 \sim 4.5$ & $4.2 \sim 5.0$ \\
\hline 4 & Ancient buildings & $0.1 \sim 0.2$ & $0.2 \sim 0.3$ & $0.3 \sim 0.5$ \\
\hline 5 & $\begin{array}{l}\text { Operating equipment of power station and central } \\
\text { control room }\end{array}$ & $0.5 \sim 0.6$ & $0.6 \sim 0.7$ & $0.7 \sim 0.9$ \\
\hline 6 & Hydraulic tunnel & $7 \sim 8$ & $8 \sim 10$ & $10 \sim 15$ \\
\hline 7 & Traffic tunnel & $10 \sim 12$ & $12 \sim 15$ & $15 \sim 20$ \\
\hline 8 & Mine roadway & $15 \sim 18$ & $18 \sim 25$ & $20 \sim 30$ \\
\hline 9 & Permanent slope & $5 \sim 9$ & $8 \sim 12$ & $10 \sim 15$ \\
\hline
\end{tabular}

TABLE 7: Calculation parameters of the blasting vibration velocity attenuation model.

\begin{tabular}{|c|c|c|c|c|c|c|c|}
\hline Date & Time & $\begin{array}{l}\text { Detonating } \\
\text { position }\end{array}$ & $\begin{array}{c}\text { Monitoring point } \\
\text { number }\end{array}$ & $\begin{array}{c}\text { Distance } \\
(\mathrm{m})\end{array}$ & $\begin{array}{l}\text { Maximum single } \\
\text { detonating } \\
\text { charge weight }(\mathrm{kg})\end{array}$ & $\begin{array}{c}\text { Proportional } \\
\text { distance }\left(\mathrm{m} \cdot \mathrm{kg}^{1 / 3}\right)\end{array}$ & $\begin{array}{c}\text { Resultant } \\
\text { velocity } \\
\left(\mathrm{cm} \cdot \mathrm{s}^{-1}\right)\end{array}$ \\
\hline \multirow{3}{*}{ 2014.4.30 } & \multirow{3}{*}{ 15:31:01 } & \multirow{3}{*}{$\begin{array}{l}+35 \mathrm{~m} \text { level 11\# } \\
\text { roadway }\end{array}$} & 4 & 55.51 & \multirow{3}{*}{570} & 6.69 & 7.54 \\
\hline & & & 5 & 66.66 & & 8.04 & 6.38 \\
\hline & & & 6 & 75.89 & & 9.15 & 4.81 \\
\hline \multirow{3}{*}{ 2014.5.1 } & \multirow{3}{*}{$15: 30: 05$} & \multirow{3}{*}{$\begin{array}{l}+35 \text { m level } 10 \# \\
\text { roadway }\end{array}$} & 4 & 64.15 & \multirow{3}{*}{570} & 7.74 & 4.35 \\
\hline & & & 5 & 73.77 & & 8.90 & 6.70 \\
\hline & & & 6 & 81.34 & & 9.81 & 5.72 \\
\hline \multirow{4}{*}{2014.5 .2} & \multirow{2}{*}{$15: 29: 58$} & $+35 \mathrm{~m}$ level $12 \#$ & 5 & 71.21 & \multirow{2}{*}{576} & 8.56 & 3.25 \\
\hline & & roadway & 6 & 82.07 & & 9.86 & 2.53 \\
\hline & \multirow{2}{*}{$15: 31: 10$} & $+50 \mathrm{~m}$ level $24 \#$ & 5 & 174.86 & \multirow{2}{*}{576} & 21.02 & 0.22 \\
\hline & & roadway & 6 & 180.09 & & 21.64 & 0.22 \\
\hline \multirow{5}{*}{ 2014.5.3 } & \multirow{3}{*}{$15: 28: 14$} & \multirow{3}{*}{$\begin{array}{l}+35 \mathrm{~m} \text { level } 12 \# \\
\text { roadway }\end{array}$} & 4 & 59.10 & \multirow{3}{*}{580} & 7.09 & 3.95 \\
\hline & & & 5 & 71.22 & & 8.54 & 3.88 \\
\hline & & & 6 & 82.08 & & 9.84 & 2.91 \\
\hline & \multirow{2}{*}{$15: 32: 23$} & $+50 \mathrm{~m}$ level $24 \#$ & 4 & 175.02 & \multirow{2}{*}{430} & 23.19 & 1.01 \\
\hline & & roadway & 5 & 174.77 & & 23.16 & 0.19 \\
\hline \multirow{4}{*}{ 2014.5.4 } & \multirow{2}{*}{$15: 30: 58$} & $+35 \mathrm{~m}$ level $10 \#$ & 5 & 68.09 & \multirow{2}{*}{520} & 8.47 & 3.82 \\
\hline & & roadway & 6 & 75.12 & & 9.34 & 3.52 \\
\hline & \multirow{2}{*}{$15: 31: 43$} & +50 m level 24\# & 4 & 175.40 & \multirow{2}{*}{556} & 21.33 & 0.04 \\
\hline & & roadway & 5 & 174.65 & & 21.24 & 0.08 \\
\hline \multirow{3}{*}{ 2014.5.5 } & 15:30:11 & $\begin{array}{l}+35 \mathrm{~m} \text { level } 11 \# \\
\text { roadway }\end{array}$ & 4 & 69.11 & 545 & 8.46 & 6.05 \\
\hline & \multirow{2}{*}{$15: 31: 09$} & $+50 \mathrm{~m}$ level $25 \#$ & 4 & 199.87 & \multirow{2}{*}{969} & 20.20 & 0.35 \\
\hline & & roadway & 5 & 211.35 & & 21.36 & 0.41 \\
\hline
\end{tabular}

According to mining blasting vibration monitoring results, the safety standard of blasting vibration and Sadov's empirical formula are applied for the analysis of multipoint differential blasting of the pillarless caving method in Baoguo Iron Mine. The results are as follows:

(1) Based on the statistical analysis of the on-site blasting vibration monitoring signals, it can be concluded that the main vibration frequencies are almost less than $10 \mathrm{~Hz}$ and the maximum safety PPV is $18 \mathrm{~cm} / \mathrm{s}$.

(2) The parameters of empirical formula are successfully determined by the minimum proportional distance, and then the suitable prediction model of safety blasting for Baoguo Iron Mine is $v=208.169$ $\left(Q^{1 / 3} / R\right)^{1.830}$. According to the safety prediction model, when the distance between the monitoring point and the detonating point decreases, the maximum particle vibration velocity of blasting vibration will tend to increase.

(3) Gradient guidance detonating charge weights are obtained by using prediction model of safety blasting for Baoguo Iron Mine. When the mining face is getting close to the main haulage roadway, especially when the distance between mining face and the main haulage roadway is less than $35 \mathrm{~m}$, the maximum single detonating charge weight should be reduced in a gradient manner.

\section{Conclusions}

Underground mine environment is extremely complex; the deformation of soft rock roadway is the result of a variety of 


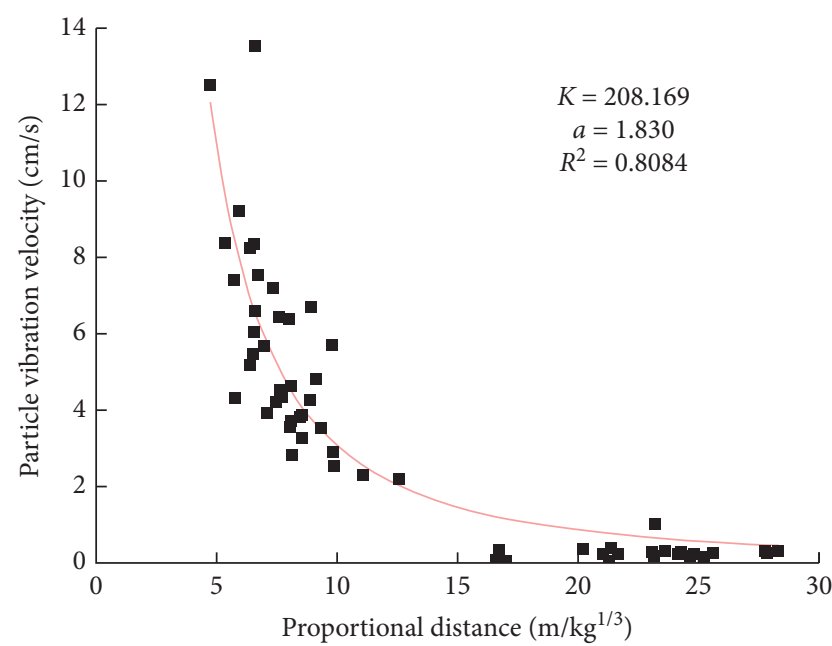

FIgURE 10: Relationship between vibration velocity and $R_{\mathrm{m}}$.

TABle 8: The maximum single detonating charge weights corresponding to different distances.

\begin{tabular}{lc}
\hline Distance $(\mathrm{m})$ & Maximum single detonating charge weights $(\mathrm{kg})$ \\
\hline 15 & 45.25 \\
20 & 107.26 \\
25 & 209.49 \\
30 & 361.99 \\
35 & 574.83 \\
40 & 858.06 \\
50 & 1675.89 \\
\hline
\end{tabular}

internal and external factors. In order to solve the problem of poor stability and large deformation of soft rock roadway, the research group comprehensively studied the deformation mechanism from the physical and structural features of rock mass, the external environment characters, the influence of clay minerals, and the cyclic mining blasting vibration load.

Through the systematic research, it is found that the characteristics of main haulage roadway are as follows: (1) The development of joint fissures and wedge-shaped structures in the vicinity of geological faults prove that the rock mass has been broken and the stability of roadway is extremely poor. (2) The surrounding rocks of the main haulage roadway belong to soft rock that is easy to swell. It has a large capacity of absorbing water and becomes destructive or detritus after encountering water and finally produces rheology phenomenon under the engineering stress. (3) In the process that the mining face gradually approaches the main haulage roadway, the original design of the mining blasting has become failed, and the inappropriate proportional distances result in excessive blasting vibration load.

All of the above factors can cause the stability of the surrounding rock in the main haulage roadway to be reduced, and they also influence each other and promote each other. The accumulated damage caused by the frequent mining blasting vibration leads to the original joint fissures in surrounding rock to expand and develop. What's more, the developed joint fissures will make the pore water in

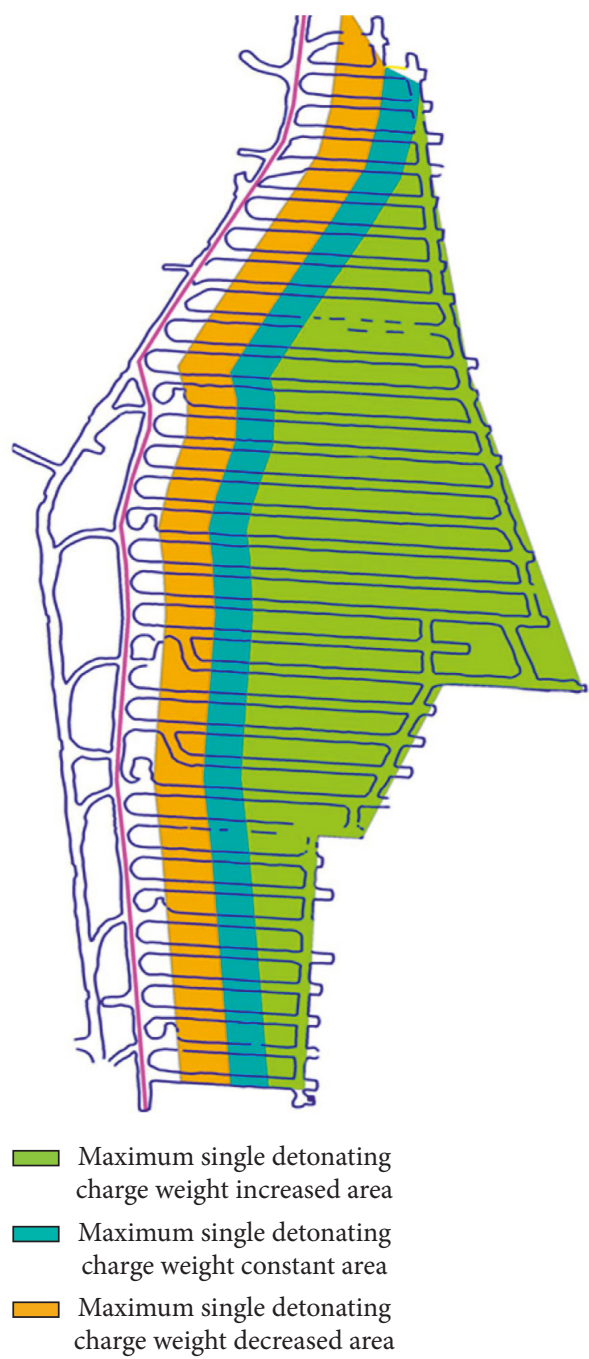

FIgUre 11: Changes of the maximum single detonating charge weights.

surrounding rock circulate more freely. Afterwards, the absorption of water intensifies the expansion of soft rock minerals. Eventually, the expansion deformation combined with frequent mining blasting load leads to the roadway supporting damaged and economic loss suffered.

\section{Data Availability}

The data used to support the findings of this study are available from the corresponding author upon request.

\section{Conflicts of Interest}

The authors declare that they have no conflicts of interest.

\section{Acknowledgments}

This work was financially supported by the project (no. 2016YFC0801605) supported by the State Key Research Development Program of China and the project (no. 51674061) supported by the National Natural Science Foundation of China. 


\section{References}

[1] R. Fenner, Untersuchungen zur Erkenntnis des Gebirgsdrucks, Glückauf, Essen, Germany, 1938.

[2] J. Kaiser, Untersuchungen über das Auftreten von Geräuschen beim Zugversuch, Ph.D. thesis, Technische Hochschule München, München, Germany, 1950.

[3] B. Ladanyi, "Use of long-term strength concept in the determination of ground pressure on roadway linings," in Proceedings of the Third International Congress on Rock Mechanics, vol. 2B, pp. 1150-1156, Denver, CO, USA, September 1974.

[4] P. W. Bridgman, "Volume changes in the plastic stages of simple compression," Journal of Applied Physics, vol. 20, no. 12, pp. 1241-1251, 1949.

[5] D. Peila, P. P. Oreste, and G. Rabajoli, "The pretunnel method, a new Italian technology for full-face roadway excavation: a numerical approach to design," Tunnelling and Underground Space Technology, vol. 10, no. 3, pp. 367-374, 1995.

[6] P. Roussev, "Calculation of the displacements and Pacher's rock pressure curve by the associative law for the fluidityplastic flow," Tunnelling and Underground Space Technology, vol. 13, no. 4, pp. 441-451, 1998.

[7] S. L. Crouch, "Solution of plane elasticity problems by the displacement discontinuity method," International Journal for Numerical Methods in Engineering, vol. 10, no. 2, pp. 1-34, 1976.

[8] T. Bienawski, Felsklassifikation: Stand der Technick and Moglichkeiten der Normung, Forschungsberichte des Transportwesens, 1981.

[9] S. M. Pandit, F. O. Otuonye, and R. X. Sun, "Spectrum analysis of a mechanical bolt system under impact by using the DDS methodology," Proceedings of SPIE-The International Society for Optical Engineering, vol. 3089, pp. 119-127, 1997.

[10] A. P. Peirce and J. A. N. L. Napier, "A spectral multipole method for efficient solution of large-scale boundary element models in elastostatics," International Journal for Numerical Methods in Engineering, vol. 38, no. 23, pp. 4009-4034, 1995.

[11] M. Eneva, "Effect of limited data sets in evaluating the scaling properties of spatially distributed data: an example from mining-induced seismic activity," Geophysical Journal International, vol. 124, no. 3, pp. 773-786, 1996.

[12] M. Ma and B. H. Brady, "Analysis of the dynamic performance of an underground excavation in jointed rock under repeated seismic loading," Geotechnical and Geological Engineering, vol. 17, no. 1, pp. 1-20, 1999.

[13] M. Ramulu, A. K. Chakraborty, and T. G. Sitharam, "Damage assessment of Basaltic rock mass due to repeated blasting in a railway roadwaying project: a case study," Tunnelling and Underground Space Technology, vol. 24, no. 2, pp. 208-221, 2008.

[14] E. K. Singh, "Blast vibration damage to underground coal mines from adjacent open-pit blasting," International Journal of Rock Mechanics and Mining Sciences, vol. 39, no. 8, pp. 959-973, 2002.

[15] Q. Li, W. Shi, and R. Yang, "Deformation mechanisms in a coal mine roadway in extremely swelling soft rock," SpringerPlus, vol. 5, no. 1, p. 1310, 2016.

[16] B. Jiang, L. Wang, and Y. Lu, "Failure mechanism analysis and support design for deep composite soft rock roadway: a case study of the Yangcheng Coal Mine in China," Shock and Vibration, vol. 2015, Article ID 452479, 14 pages, 2015.
[17] S. C. Li, Q. Wang, and H. T. Wang, "Model test study on surrounding rock deformation and failure mechanisms of deep roadways with thick top coal," Tunnelling and Underground Space Technology, vol. 47, no. 10, pp. 52-63, 2015.

[18] Chinese National Standard, GB6722-2014 Safety Regulations for Blasting, State Standardization Publishing House, Beijing, China, 2014. 


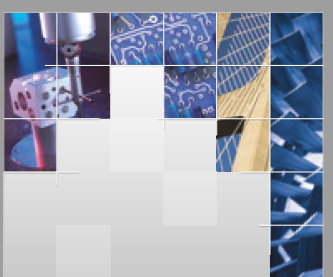

\section{Enfincering}
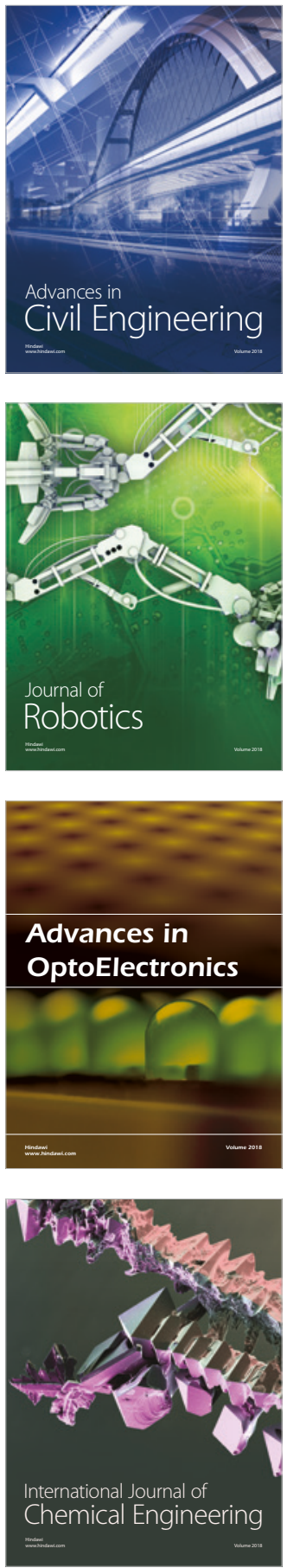

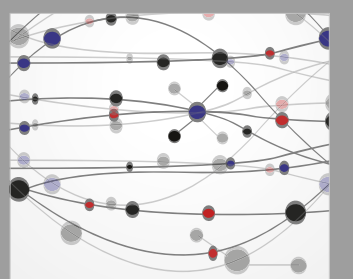

\section{Rotating \\ Machinery}

The Scientific World Journal

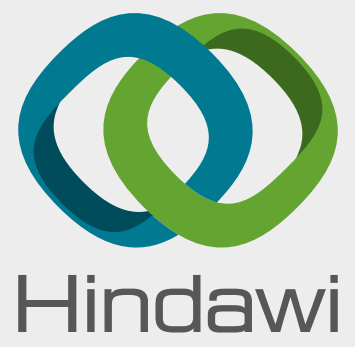

Submit your manuscripts at

www.hindawi.com
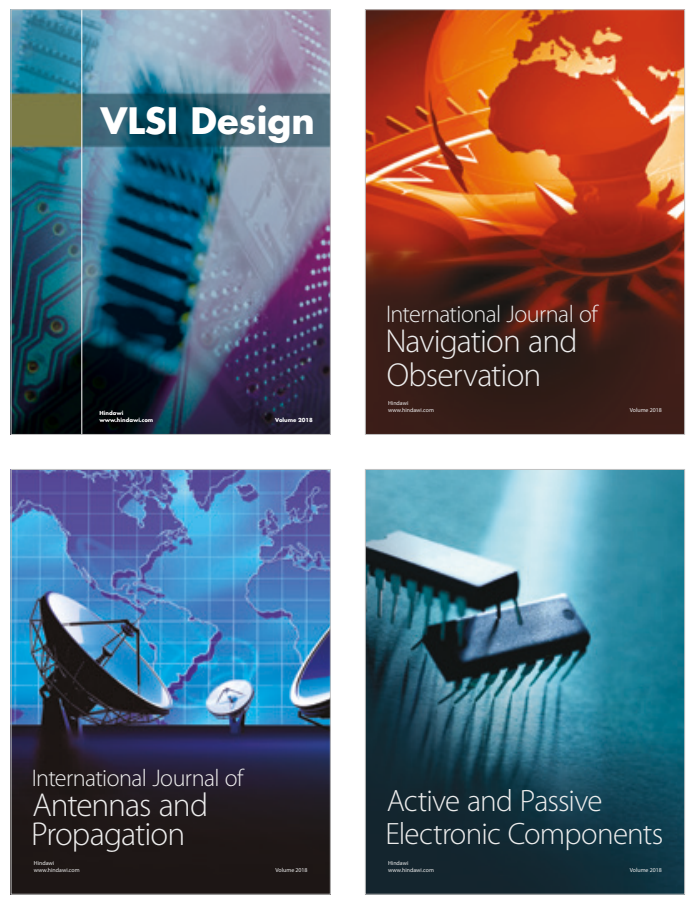
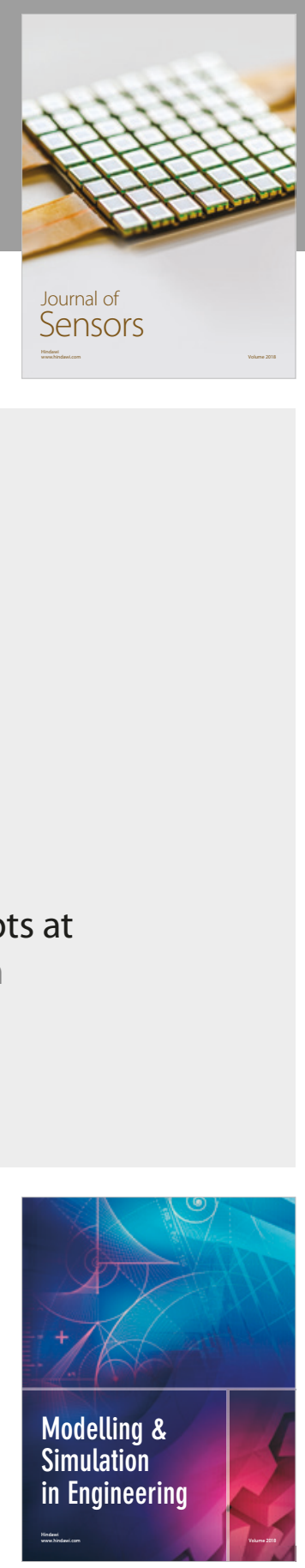

\section{Advances \\ Multimedia}
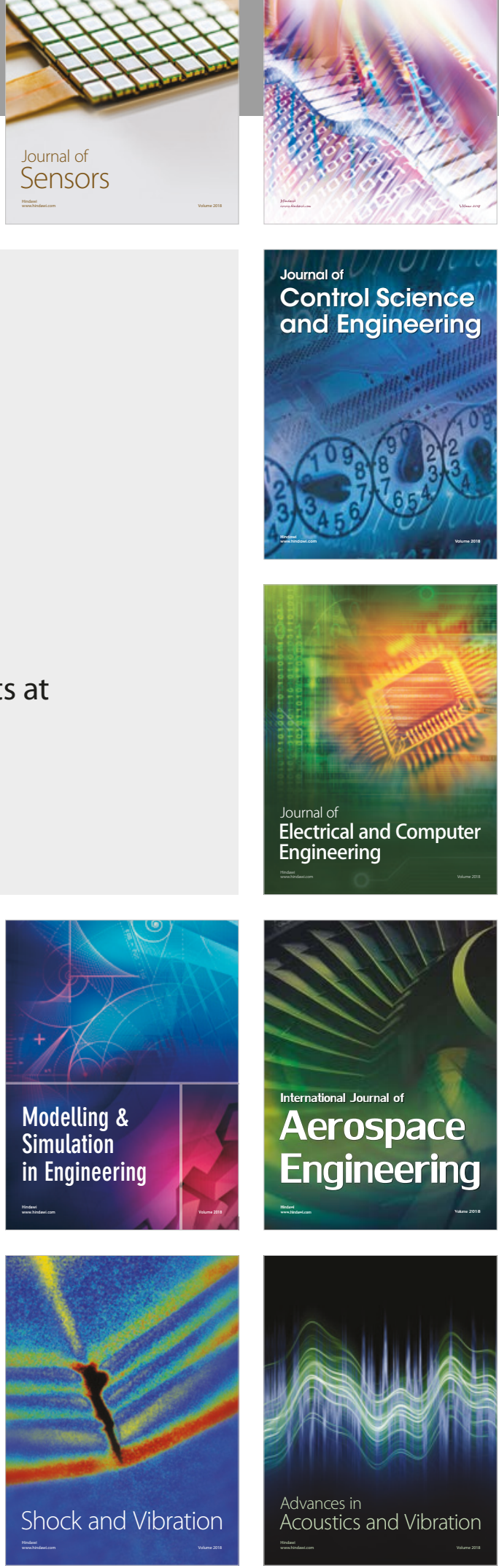